\title{
Visualization of Transit Mobility and Performance
}

\author{
Anibal A. Galindez, Los Angeles County \\ Metropolitan Transportation Authority \\ Ricardo Mireles-Córdova, Los Angeles Unified School District
}

\begin{abstract}
The visualization of a transit mobility model is presented in this article. The method described shows transit system capacity and utilization by area and time of day using ride-check data as a proxy for real-time information. It indicates how public transportation resources can be used in a more efficient and effective manner.

The visualization process requires the creation of a time/location data matrix of the variable to be analyzed and the linking of the performance measure to spatial data. This creates a temporal Geographic Information System (GIS) platform for the entire transit system or systems at the regional level. The GIS is "animated" to show snapshots of the system in sequence for the entire day. It serves as a powerful tool to evaluate bus route performance.

The visual display of transit system utilization facilitates the assessment of where, when, and what type of resources should be allocated to maximize transit utilization at the lowest possible cost. It also can serve as a graphical tool to inform the public and policy-makers about transit system performance. Different demand markets for transit (rail, bus fixed-route, shuttles, community circulators, vanpools, etc.) can be appraised and the effectiveness of current transit in serving these markets can be visualized. The method can be used to show where service can be allocated, thus enhancing the mobility of transit systems.
\end{abstract}


This article seeks to visualize the utilization of transit resources. Ideally, the mechanics of transportation system design and supply would be subject to continuous evaluation and refinement using an integrated scheme of automatic vehicle locators (AVLs), automatic passenger counters, and automated fare collection equipment. Currently, most transit agencies do not have this technology and rely instead on manual or semiautomated ride checks collected periodically. In lieu of real-time data, it is generally agreed that a ride check provides the most comprehensive set of data for operational and transit planning purposes. The methodology proposed in this article uses the ride check to visualize transit system performance by time of day and geographic area.

\section{Introduction}

A GIS has been defined as:

the organized activity by which people: (1) measure aspects of geographic phenomena and processes; (2) represent these measurements, usually in the form of a computer database, to emphasize spatial themes, entities, and relationships; (3) operate upon these representations to produce more measurements and to discover new relationships by integrating disparate sources; and (4) transform these representations to conform to other frameworks of entities and relationships. (Chrisman 1997)

A comprehensive treatment of GIS, an emerging multidisciplinary technology, is beyond the scope of this article. An understanding of GIS requires, at a minimum, knowledge about attribute and spatial measurement and the representation of this measurement; different kinds of operations and transformations that can be applied to spatial entities and attributes; and the evaluation and implementation of the GIS within social and institutional contexts. An account of these particulars can be found in Chrisman and the references cited therein.

Geographic information is commonly broken into the components of time, space, and attribute (when, where, and what.) Most GIS is organized with time held constant. Experience shows that attributes change with time. For example, overcrowding on a transit line is usually a temporal phenomenon. This condition is dynamic and occurs at certain locations and time periods. A static GIS does not allow the viewer to see these changes and their interactions within the transportation system. 
A temporal GIS, by storing information that changes with time, is able to answer questions such as where and when do the attributes or spatial objects change, what patterns may be observed, and what might be the underlying causes of these changes. Temporal GIS data can be visualized by "animating" the attribute information within a user-controlled, time-period sequence. The analysis can be done from a customer, transit agency, and/or regional perspective.

The GIS allows for the analysis of contiguous areas instead of discrete transit routes. It also serves as the basis for the creation of a street centerline GIS dataset that incorporates the transit route information as a network. This system would be amenable to network analysis questions such as assignment of routes to garages to minimize deadhead time. Current GIS software has the capability of performing network operations that can be used to evaluate service coverage and the minimization of aggregate walking time to transit stops. Another application would be efficient schedule adjustments for multiple time transfers.

The GIS serves as an aid in the design of transit systems. A system redesign should incorporate origin and destination surveys, trip diaries, and other forms of customer information. This allows explicit demand-side elements to be incorporated in the analysis. As an example, the survey data could be visualized and the system investigated for areas where passenger demand justifies nonexistent direct connectivity between travel points to minimize travel time.

\section{Methodology}

In the transit mobility model visualization, the ride-check data must be formatted as time/location matrices of the variables to be analyzed. These matrices are then imported into a GIS. A temporal GIS is created by sequentially displaying the map snapshots through animation software.

The method requires that the ride-check data have geocoded bus stops. The weekday ride-check data used were collected between December 1995 and August 1998. The data were organized by route and the ridership attribute information such as boardings, alightings, load ratios, schedule adherence, etc. summarized by stop and time period. This procedure creates a time of day/tran- 
sit stop location matrix of the variable of interest. The matrix can be generated through relational database, statistical, or mathematical software packages, or in-house computer programming.

Activity at a bus stop is what is known in GIS terminology as an "event." The process of geocoding takes an event's locational reference and matches it to a map that contains a spatial representation of the location. The reference to a location could be one of several types: a x, y (and z) coordinate, an address, or a measure along a route. A layer of geographic information is a collection of geographic features such as rail tracks, roads, transit routes, bus stops, municipalities, etc. The same type of shape-either points (bus stops), lines (routes), or polygons (cities)-represents these features. The geocoded bus stop data provide the link that ties the ridership information to the GIS platform. The $x, y$ coordinates of the bus stops can be linked in the database to attribute information about the bus stop such as transfer possibilities, landmarks, amenities, etc.

Graphic files with the variables and information of interest for particular time periods are generated in the GIS. These "snapshots" of the area are shown within a user-controlled time window sequence to produce the computer "animations." Passenger flow volumes on streets served by multiple routes can be depicted through three-dimensional graphics. The "animation" can be done as a slide show in a presentation software program, with "dynamic graphic engine" software or graphical simulation software packages.

The model is useful for presenting and analyzing complex bus route and transit system information. Among the advantages of using a GIS platform is the ability to tie the model information to other transit-related databases. This permits the overlay of geographic (schools, hospitals, shopping centers, etc.) and census-tract or block-level demographic features (income, auto availability, likelihood of transit dependency, etc.) to the ridership data on a map as well as operational peculiarities of the different transit routes.

The data can be aggregated to compute selected summary statistics by areas such as demographics, percentage of overcrowded bus stops and of impacted patronage, and economic/productivity numbers. GIS methods for statistical work permit the detailed treatment of statistical information using cus- 
tom designed polygons. The interactions between transit lines and the synergies of the transit system are assessed through the spatial-temporal variability of the attributes at the bus stop, route, and area polygon level.

Aerial photography can aid in the visualization of land-use patterns and in the construction of a typology of transit markets based on geographic/demographic factors. The GIS shows the relationships between different phenomena that affect transit supply and demand. An innovation of the methodology lies in allowing the visualization of multiple evaluation criteria simultaneously. In the following section, the methodology is applied to the service region of the Los Angeles County Metropolitan Transportation Authority (MTA).

\section{Visualization Model}

Los Angeles County is one of the nation's largest counties with 4,083 square miles $\left(11,077 \mathrm{~km}^{2}\right)$, of which $1,421 \mathrm{mi}^{2}\left(3,855 \mathrm{~km}^{2}\right)$ are incorporated areas. These areas represent 88 cities. The county is larger in population than 42 states in the nation, with more than 9.8 million people as of January 2000 , of which all but 1 million live in the cities. However, it has the lowest density of the 20 largest population centers of the world (World Almanac and Book of Facts 1995). This urban sprawl yielded an estimated 85.8 percent drive-alone and carpool weekday worktrips with a 6.5 percent transit share in Los Angeles County, according to the 1990 census.

The Los Angeles County MTA is the regional light rail, heavy rail, and largest bus operator, providing 1,440 square miles $\left(3,907 \mathrm{~km}^{2}\right)$ of service coverage in almost all of the cities and noncontiguous portions of unincorporated Los Angeles County. The agency is the second largest bus operator in North America in terms of unlinked passenger trips (American Public Transit Association 2000). Ninety-one percent of MTA boardings are made in the bus system.'

Boardings take place on 127 transit lines that have an average length of 24 miles (40 kilometers). The lines carry approximately 300,000 customers that generate about 1.1 million boardings on an average weekday. Trip lengths vary by line and type of service, but the systemwide average trip length is 3.7 miles (6 kilometers). A high transfer rate is a by-product of the system's grid 
design. The central business district (CBD) of Los Angeles is the transit center where lines connect for regional travel. The CBD of Los Angeles generates only 6 percent of the employment in the county (City of Los Angeles Planning Department 1995).

The agency directly operates or contracts 1,930 peak vehicles on a typical weekday. These vehicles are scheduled to deliver 20,400 revenue hours that cover 252,000 revenue miles (405,458 revenue kilometers). Directly-operated service represents 93 percent of the revenue hours and peak vehicles. Almost all MTA buses are 43-seat vehicles. In addition to the MTA, there are 12 regionally significant municipal bus operators and several local paratransit providers whose service coverage overlaps the MTA's in certain areas. The MTA carries approximately 80 percent, or 4 out of 5 , of the annual unlinked bus passenger trips.

The MTA ride-check database was summarized by census tract for the entire day. The census tract is a polygon containing all the transit attribute information of the bus stops within it in addition to demographic data. The population and employment densities of Los Angeles County are presented in Figures 1 and 2. The Central Limit Theorem of statistics allows us to do this based on the large number of census tracts $(1,642)$ involved (Draper and Smith 1981). Areas where the standard deviation is one or more above the mean represent areas where the population and employment are highly concentrated.

These maps closely mimic the location of households below the county's median income. The GIS can be used to pair the locations where a high concentration of jobs exists and the residences of likely jobholders. The system can be assessed to see how well it connects these markets and whether some routes can be restructured to better serve these clients.

The areas where boarding density (bus boardings/square mile) are the highest are shown in Figure 3 . The top 45 lines carry 85 percent of the boardings and the top 20 lines carry about half the weekday boardings. The Gaussian distribution, as shown in Figure 3, closely represents this fact. It shows areas where high-capacity transit could be currently implemented to improve bus service for the greatest number of customers. 


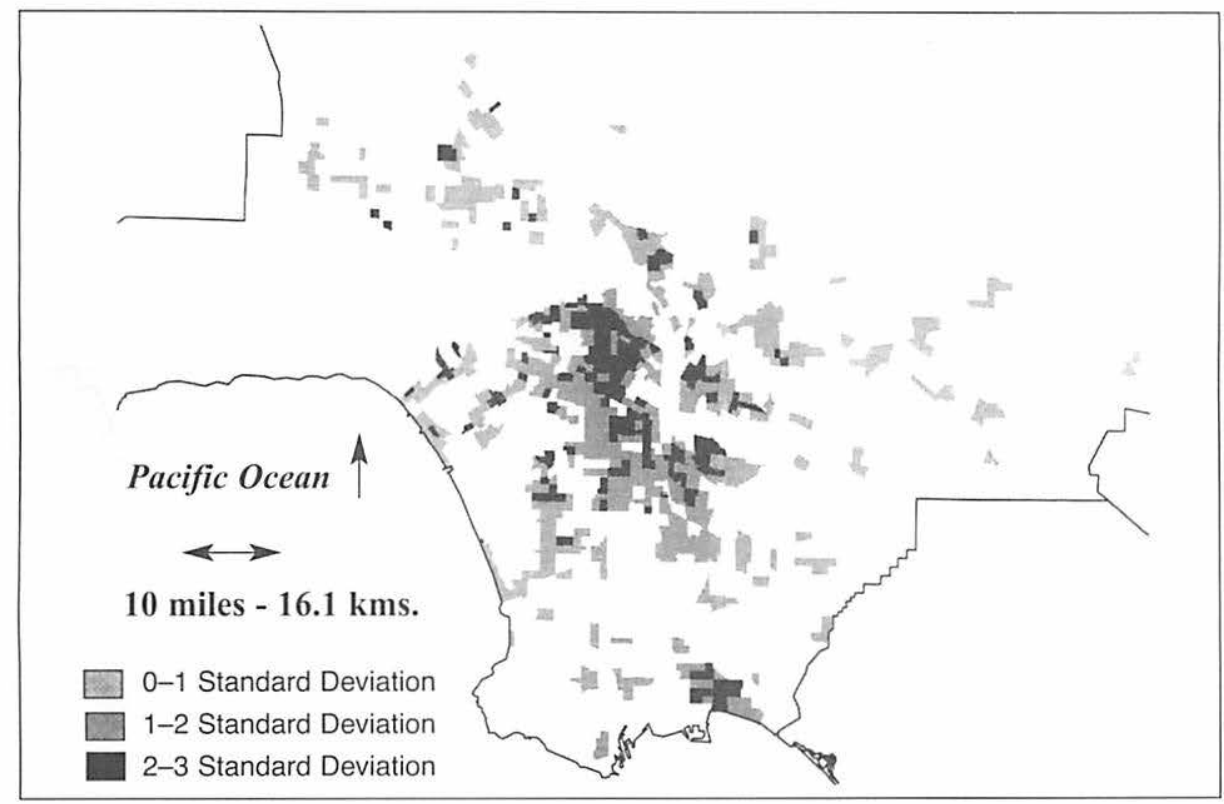

Source: 1990 Census STF3 File.

Figure 1. Los Angeles County population density

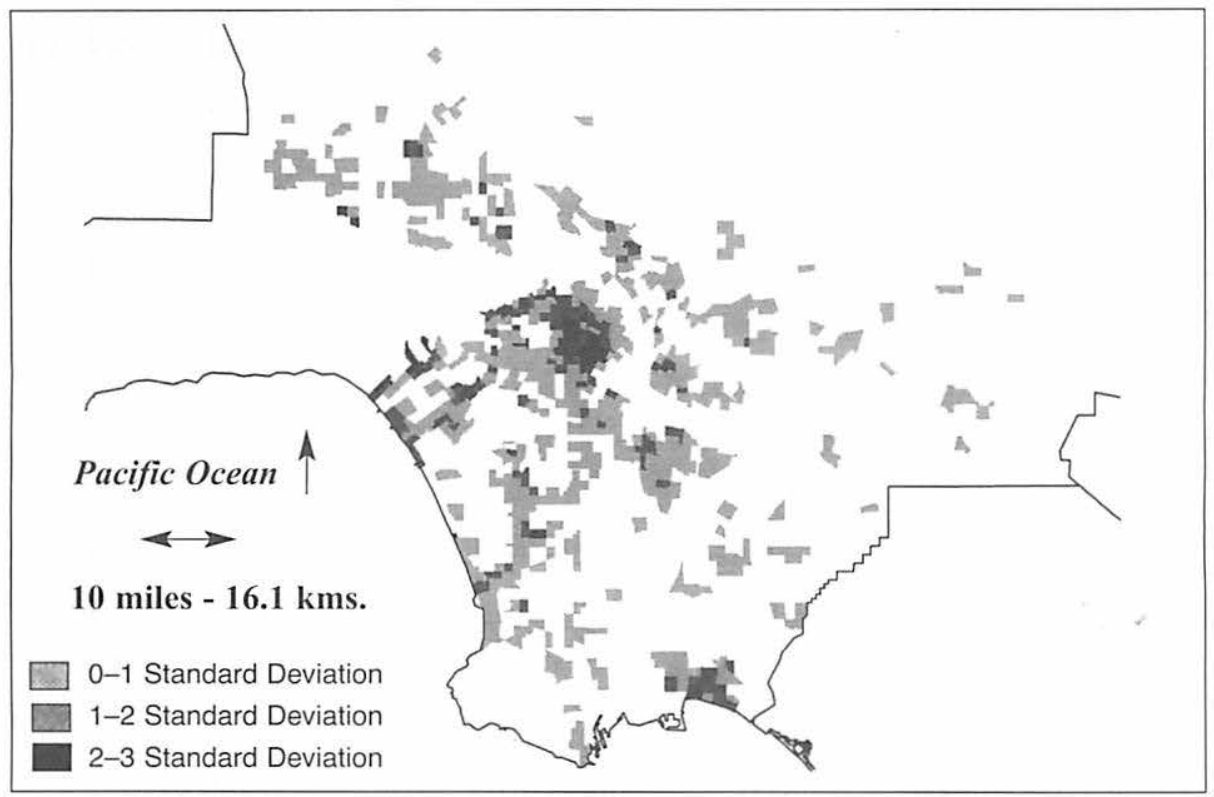

Source: 1990 Census STF3 File.

Figure 2. Los Angeles County employment density 


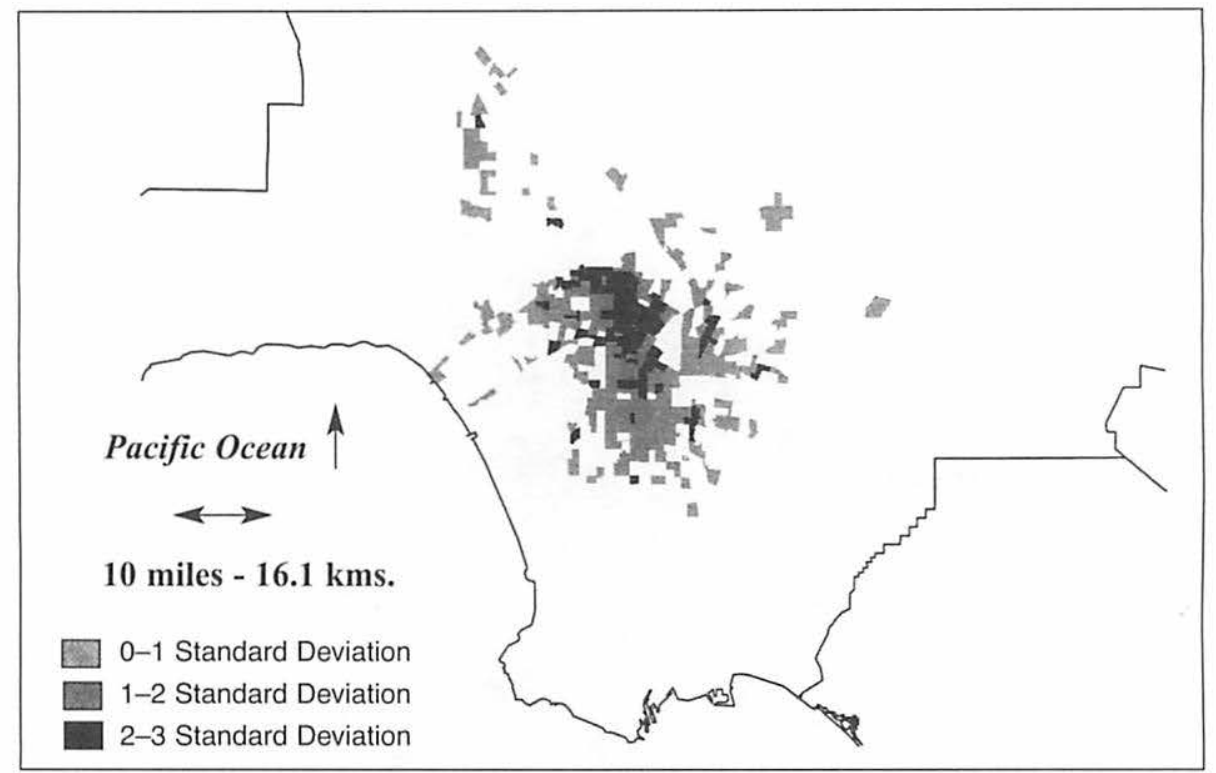

Source: MTA Ride Check Database.

Figure 3. Los Angeles County MTA bus boardings/square mile

The proxy variable used to visualize transit demand was the number of patrons onboard vehicles by time period and location. Transit supply was assessed through the number of seats offered by time period and location. These variables were summarized by 20 -minute and census tract data for the entire day from the geocoded bus stops for each line. The ratio of the patrons onboard to the number of seats offered is known as the "load ratio." Load ratios below 0.5 indicate locations and time periods where smaller vehicles (22-seat vans or shuttle buses) can be used to satisfy demand, since almost all MTA buses have an average of 43 seats. This is shown in Figure 4 for the peak direction of the lines.

These figures show the concentrated load ratios of the lines by census tract. The centers of these figures, which picture the downtown area, are where the load ratios are highest. This can be displayed with a three-dimensional graphic that takes into account the individualized route and its load ratio height. It can then be seen that lines traversing these areas are heavily crowded in one direction, and that the western portion of the county is the result of severe overcrowding on just one to three buses. 


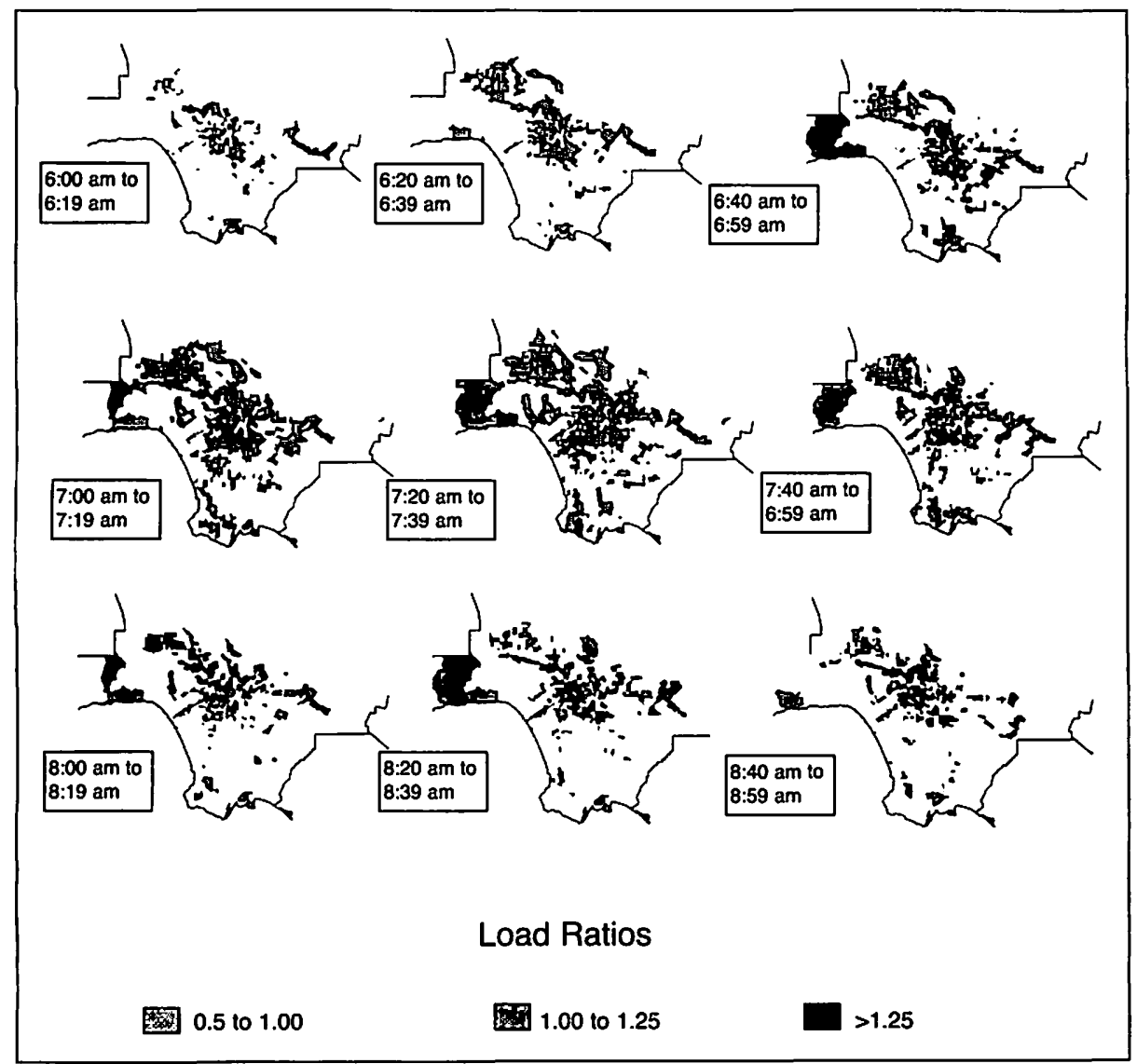

Figure 4. Average Load Ratios-average weeklay A.M. peak direction

The temporal pockets of overcrowding on major streets seen in the route visualizations can be abated by trippers that do not run the entire route length or by jitney/van service. The latter was done in the past on streets where overcrowding currently occurs (Teal and Nemer 1986). Conversely, population density and land-use patterns in certain areas do not support traditional transit service, yet there are unmet travel needs that could be accommodated with shuttles, vans, or taxis.

Poor vehicle utilization can be caused by several factors. On some routes, more service is offered than time-of-day demand warrants. Other routes have heavy demand in one direction but much less in the other, yet the vehicles complete round-trips. In certain areas, there are community circulators that take 
away the demand for shorter length trips. Another possible cause for underutilized vehicles is infrequent service that is lightly used. Creative scheduling strategies, like interlining and turn-backs which are done at the MTA, can be visualized with this methodology. The analysis needs to incorporate the ridership information of the municipal operators to be complete since they offer overlapping service at different prices.

\section{Conclusions}

The temporal GIS presented in this article can be used to assess the effectiveness and efficiency of transportation options at the regional, transit agency, and route level. The method uses off-the-shelf software and it is immediately useful to transit agencies with ride-check information. The end-products of the methodology provide the tools necessary to inform elected officials, who fund transportation programs, and the public on current transit usage and to generate support for creative public transportation policies. The application of the methodology elsewhere and the sharing of the analytical results are encouraged.

\section{Further Research}

The methodology presented here uses off-the-shelf software to visualize transit system performance with preexisting data. There is a need for an integrated software product connected to a Global Positioning Satellite (GPS) transponder collecting real-time data from transit vehicles in a continuous fashion. The enormous amount of data collected by these devices needs to be filtered to produce the visualizations presented here. These can serve as prototypes for product results.

The software would integrate AVLs, automatic passenger counters, and automated fare collection through the GPS, and depict the transaction outputs as a temporal GIS. Issues such as hardware compatibility and open connectivity standards for emerging technologies need to be addressed. As an example, the AVL portion of the hardware could be tied to computer-aided dispatch to maximize efficiency. This product could serve as the basis for establishing specifications that could advance a standard for the transit industry. 


\section{Acknowledgments}

The authors wish to thank Julian Burke, chief executive officer of the MTA; James de la Loza, executive officer for countywide planning; and James McLaughlin, director of transit planning, for their support. An appreciation is extended to Thomas Amiya, Mauro Arteaga, Kathy Hesseltine, and Devang Parikh for their technical assistance. Six anonymous reviewers are thanked for their constructive suggestions. The opinions contained in this article are solely those of the authors and do not represent the official view of the Los Angeles County MTA.

\section{Endnote}

1. The MTA statistics were obtained from the annual ridership data in effect from June 1999.

\section{References}

American Public Transit Association. 2000. APTA 2000 transit fact book. APTA, Washington DC, p. 111.

Chrisman, Nicholas. 1997. Exploring Geographic Information Systems. John Wiley \& Sons, NY, p. 5.

City of Los Angeles Planning Department. 1995. Citywide general plan frameworksocioeconomic impact assessment report. City of Los Angeles, p. 26.

Draper, N. R., and H. Smith. 1981. Applied regression analysis. John Wiley \& Sons, NY, p. 8.

Teal, Roger F., and Terry Nemer. 1986. Privatization of urban transit: The Los Angeles jitney experience. Transportation 13. Martinus Nijhoff Publishers, Dordrecht, Holland, p. 5-22.

U.S. Census Bureau and U.S. Department of Commerce from World almanac and book of facts 1995. Funk \& Wagnalls Corporation, Mahwah, NJ, p. 840. 


\section{About the Authors}

ANibal A. Galíndez (galindeza@hotmail.com) is a transportation project manager in the transit planning unit of the countywide planning division at the Metropolitan Transportation Authority. He is currently involved in data mining, ITS, and the examination of variables for their inclusion into a regional planning network. He holds a master's degree in operations research/applied statistics from the University of Miami.

RiCardo Mireles-Córdova (rmc@magi.net) is an information services director in the facilities planning division of the Los Angeles Unified School District. He holds a bachelor's degree in anthropology from Columbia University. He is presently engaged in the development of web-based information tools. 